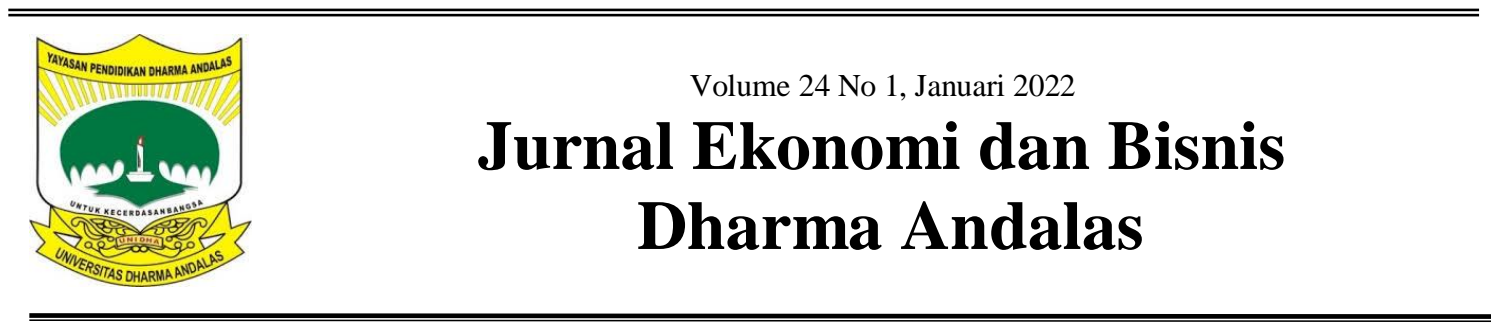

\title{
Literasi Keuangan dan Literasi Digital UMKM Kuliner Kota Padang Sebagai Penggerak Pemulihan Ekonomi Masa Pandemi Global Covid 19
}

\author{
Yenni Del Rosa ${ }^{1}$, Idwar ${ }^{2}$, Mohammad Abdilla \\ Fakultas Ekonomi dan Bisnis Universitas Dharma Andalas ${ }^{1,2,3}$ \\ email; yennidelrosa62@gmail.com ${ }^{1}$ \\ idwar68@unidha.ac.id ${ }^{2}$ \\ m.abdilla@yahoo.co.id ${ }^{3}$
}

\begin{abstract}
The purpose of the study was to look at the effect of financial literacy and digital literacy on the turnover of culinary SMEs in Padang City during the covid 19 pandemic partially and simultaneously. The research method used an associative method with a quantitative approach. The research population was 371 samples, 193 were taken by purposive sampling. Data collection techniques with field research, interviews, observations and questionnaires. All research variables meet all instrument tests and classical assumption tests. The results of the multiple linear regression equation obtained $Y=1.657+0.539 X 1+0.723 X 2+e$. Testing the hypothesis partially and simultaneously at a significance level of $5 \%$ shows that financial literacy and digital literacy have a significant positive effect on the turnover of culinary SMEs in the city of Padang. The correlation between financial literacy and digital literacy with culinary SMEs turnover is 0.796 (strong), $R^{2}=0.633$ and Adjusted $R$ square $=0.625$
\end{abstract}

Keywords : financial literacy, digital literacy, SMEs

\begin{abstract}
ABSTRAK
Tujuan penelitian melihat pengaruhliterasi keuangan dan literasi digital terhadap omset UMKM kuliner kota Padang saat pandemic covid 19 secara parsial dan simultan. Metode penelitian memakai metode asosiatif dengan pendekatan kuantitatif. Populasi penelitian 371sampel 193 diambil secara purposive sampling. Teknik pengumpulan data dengan field research, wawancara, observasi dan angket. Semua variabel penelitian memenuhisemua uji instrumen dan uji asumsi klasik. Hasil persamaan regresi linier berganda didapat $\mathrm{Y}=1,657+0,539 \mathrm{X}_{1}+$ $0,723 \mathrm{X}_{2}+$ e. Uji hipotesis secara parsial dan simultan pada tingkat signifikansi $5 \%$ menujukkan literasi keuangan dan literasi digital berpengaruh positif signifikan terhadap omset UMKM kuliner kota Padang. Korelasi literasi keuangan dan literasi digital dengan omset UMKM kuliner 0,796 (kuat) dan $\mathrm{R}^{2}=0,633$ serta Adjusted $\mathrm{R}$ square $=0,625$
\end{abstract}

Keywords: literasi keuangan, literasi digital, UMKM 


\section{PENDAHULUAN}

Pandemi covid 19 saat ini sangat mempengaruhi kinerja UMKM dari sisisupply dan demand, apalagi saat ini pemerintah mulai memberlakukan adanya Pemberlakuan Pembatasan Kegiatan Masyarakat (PPKM). Kepemilikan smartphone serta penetrasi internet cukup tinggi sehingga Indonesia memiliki potensi ekonomi digital cukup besar karena jumlah penduduknya sangat banyak turut mendorong produktivitas UMKM. Perkembangan ekonomi digital memberikan tantangan tersendiri terhadap kinerja UMKM sebagai tulang punggung ekonomi Indonesia karena kurangnya kemampuan pelaku UMKM memanfaatkan teknologi digital dalam memasarkan produk/jasa lainnya. Keterbatasan infrastruktur dan tenaga kerja kurang terampil juga menjadi kendala bagi perkembangan ekonomi digital nasional.

UMKM berperan penting dan strategis dalam struktur perekonomian nasional karena kontribusinya cukup besar terhadap Produk Domestik Bruto (PDB) sekitar $61,1 \%$, penyerapan tenaga kerja sekitar 97,1\% dan ekspor sekitar 14,4\%. Struktur ekonomi Indonesia saat ini masih didominasi oleh usaha mikro dengan porsi mencapai $99 \%$ dan UKM masih tergolong sedikit kontribusinya hanya berasal dari pelaku industri besar sekitar 1\%. Saat pandemi covid 19 berdampak paling besar terhadap penurunan omset UMKM kuliner karena pemasarannya sebagian besar bersifat offline dan banyak usaha yang tutup. Kolaborasi pemerintah dan pelaku industri digital diharapkan dapat mengatasi tantangan-tantangan di atas untuk mendorong pekembangan ekonomi digital serta kinerja UMKM nasional yang lebih baik saat pandemi covid 19 . Kolaborasi digitalisasi merupakan usaha untuk meningkatkan akses terhadap berbagai layanan keuangan serta ekosistem ekonomi digital sehingga membantu UMKM nasional bertahan dan tumbuh saat pandemi covid 19. Kementerian UMKM dapat bekerja sama dengan salah satu unicorn dalam memfasilitasi pemasaran digital sehingga UMKM dapat kembali bangkit dengan mendorong keterlibatan pelaku UMKM dalam proses digitalisasi. Menurut (Bank Indonesia, 2019) baru sekitar 4,3 juta pelaku UMKM terintegrasi dengan sistem transaksi daring berupa digitalisasi pada sistem pembayaran menggunakan QRIS (QR Code Indonesia). Pemerintah melakukan revitalisasi melalui digitalisasi UMKM tidaklah mudah karena di beberapa daerah terpencil keterbatasan akses internet menjadi kendala utama.

Literasi keuangan dan literasi digital merupakan hal yang sangat dibutuhkan saat pandemi covid 19. Titik krusial tantangan digitalisasi UMKM di Indonesia, rendahnya tingkat literasi keuangan dan literasi digital. Hasil Survei Nasional Literasi Keuangan (SNLK, 2019) menunjukkan tingkat literasi keuangan masyarakat Indonesia 38,03\% jauh di bawah negara Singapura, Malaysia dan Thailand. Tahun 2020 meningkat $40 \%$ (OJK, 2020) sudah termasuk kategori well literate. Indeks literasi keuangan rata-rata nasional hanya 29,7\% kondisi ini menunjukkan bahwa pengetahuan masyarakat tentang seluk beluk keuangan tidak merata di seluruh provinsi. Paling tinggi indeks literasi keuangan masyarakat $40 \%$ di DKI Jakarta dan paling rendah 19,3\% di provinsi Papua Barat (OJK, 2016). Literasi keuangan penduduk Indonesia yangwell literate $21,84 \%$, suffiecient literate $75,69 \%$, less literate $2,06 \%$ dan not literate $0,41 \%$ (OJK, 2013).

Literasi keuangan rendah memberi gambaran terdapatnya persoalan dalam pengetahuan, cara pandang dan perilaku keuangan 
masyarakat. Rendahnya tingkat literasi keuangan pemilik UMKM tidak hanya merupakan persoalan saat ini tapi juga menjadi problem masyarakat di masa yang akan datang karena berdampak negatif terhadap perilaku keuangan. Rumah tangga yang tidak literate cenderung meminjam dengan tingkat suku bunga tinggi dan memiliki aset rendah (Lusardi, Tufano \& Mitchell 2009), kurang terlibat dengan sistem keuangan formal (Cole, Sampson \& Zia, 2009), diversifikasi resiko rendah, alokasi portofolio tidak efisien dan jumlah tabungan sedikit (Jappelli \& Padula, 2013), diversifikasi resiko dan alokasi porto folio tidak optimal serta persaingan yang tidak sehat di pasar sebagai penghalang intermediasi keuangan yang efektif. Rendahnya literasi keuangan juga membuat mekanisme pasar dan produk-produk keuangan baru serta turunannya semakin kompleks sehingga beresiko kehilangan uang akibat ketidaktahuan atau asimetri informasi yang terjadi antara informed people dan uninformed people (Jappeli, 2010).

Kurangnya kemampuan UMKM memanfaatkan teknologi digital dalam memasarkan produk/jasa merupakan tantangan tersendiri bagi UMKM. Sebanyak 64,2 juta UMKM ternyata sekitar 36\% UMKM nasional masih menggunakan metode pemasaran konvensional dan $18 \%$ UMKM menggunakan media sosial dan website untuk promosi produk. Sebanyak 37\% UMKM hanya mampu mengoperasikan komputer dan internet secara sederhana juga 29,18\% UMKM di pulau Jawa dan 16.6\% UMKM di luar pulau Jawa sudah memanfaatkan pemasaran digital (Kementerian Koperasi dan UMKM, 2020). Para pelaku UMKM perlu mengadopsi digitalisasi untuk menjaga produktivitas dan mempertahankan omsetnya di tengah pandemi covid 19.
Penetrasi penjualan digital bisa menjadi strategi utama karena dapat memperluas jangkauan pasar. Umumnya pelaku UMKM kurang berpendidikan dan gagap teknologi informasi serta internet sehingga peluang dalam proses digitalisasi tidak besar. Dengan segala keterbatasan ini bisa dipastikan tidak banyak pelaku UMKM mampu beradaptasi dengan situasi pandemi covid 19 karena membangun kemampuan literasi digital bukanlah hal yang bisa dilakukan secara instan. Pemahaman pelaku UMKM terhadap kegunaan teknologi informasi, pemasaran daring masih terbatas, proses produksi dan akses pasar daring masih belum maksimal sehingga tidak banyak peluang yang bisa dimanfaatkan pelaku UMKM untuk memberdayakan UMKM nya.

Banyak pelaku UMKM belum siap memasuki era digitalisasi, diakui atau tidak masih banyak konsumen merasa tidak aman dalam melakukan transaksi digital sehingga tidak sesuai dengan harapan konsumen berhubungan dengan kualitas produk. Akibat pandemi covid 19 sejak Maret 2020 hampir 90\% para pelaku UMKM Indonesia drastis mengalami penurunan omset dan $75,2 \%$ usaha mikro mengalami kesulitan untuk mendapatkan kredit pembiayaan guna memulai usahanya kembali. Hal ini merupakan sebuah tantangan bagi pemilik UMKM selama pandemi covid 19 dalam mengatasi masalah cash flow operasional dan isu perubahan strategi bisnis untuk menawarkan jasa/produk karena sulit beradaptasi. Hingga Maret 2021 lebih dari 15 juta pelaku UMKM telah melakukan onboardingtergabung melalui Gerakan Nasional Bangga Buatan Indonesia (GGBI) guna meningkatkan literasi digital pelaku UMKM.

Para pelaku UMKM kuliner kota Padang drastis mengalami penurunan omset tapi masih bisa tetap bertahan. 
Kuliner merupakan usaha bisnis yang sedang berkembang di kota Padang dengan berbagai jenis makanan dan minuman, wisata kuliner dan trend kuliner sebagai bukti bahwa bisnis kuliner diprediksi dapat berkembang dengan pesat. Sebanyak 163.713 sektor UMKM makanan, minuman, industri kreatif, pertanian dan 62,9 juta terancam kehilangan penghasilan akibat terdampak pandemi covid 19 (Dinas Koperasi dan UMKM, 2020). Salah satu jenis UMKM kuliner kota Padang berupa Industri Makanan Ringan (IMR) tersebar pada 11 kecamatan, paling banyak di kecamatan Padang Barat 371 buah, paling sedikit di kecamatan Lubuk Begalung 100 buah seperti pada tabel 1 .

\section{Tabel 1}

\section{Jumlah Pelaku UMKM Jenis IMR} Kota Padang Tahun 2020

\begin{tabular}{llc}
\hline No & Kecamatan & Jumlah IMR \\
\hline 1 & Padang Barat & 371 \\
2 & Padang Timur & 229 \\
3 & Padang Selatan & 226 \\
4 & Padang Utara & 322 \\
5 & Koto & 128 \\
& Tangah & \\
6 & Lubeg & 100 \\
7 & Pauh & 191 \\
8 & Luki & 294 \\
9 & Kuranji & 156 \\
10 & Nanggalo & 203 \\
11 & Bungus Teluk Kabung & 228 \\
\hline & Total & $\mathbf{2 . 4 4 8}$ \\
\hline
\end{tabular}

Sumber : Dinas Koperasi dan UMKM Kota Padang, 2021.

Persoalan UMKM kuliner jenis IMR kota Padang khususnya UMKM Minang sbb : 1) Cepat puas dengan adanya batasan mindset ; 2) Produksi mengandalkan local genuine dan minim inovasi sehingga daya saing rendah seharusnya registered inovation ; 3) Bersaing sesama jenis sehingga kompetisi pada produk yang sama mematikan yang lain dengan sistem etatism internal dimana seharusnya ada kolaborasi ; 4) Unbankable, sulitnya akses pada pembiayaan untuk ekspansi ; 5) Modal sosial berperan negatif terhadap perkembangan usaha sehingga terbatasnya enterpreneur baru untuk menghasilkan ide-ide cemerlang. Kesimpulannya hampir semua produk UMKM Sumatera Barat kalah bersaing dengan produk sejenis yang dihasilkan oleh provinsi lain dan bersaing satu sama lain serta enggan bersinergi.

Sebagai penggerak pemulihan ekonomi perkembangan media digital memberikan peluang untuk meningkatkan bisnis e-commerce karena Indonesia salah satu pengguna internet terbesar berpeluang menciptakan 1.000 technopreneurs dengan nilai bisnis USD 10 miliar dan nilai $e$-commerce mencapai USD 130 miliar tahun 2020. Para pelaku UMKM harus mampu beradaptasi dimana kapabilitas adaptif sangat krusial untuk memperkuat ketahanan UMKM saat pandemi covid 19. Menurut (Sulistyawan, 2020) beberapa resiko keberlansungan UMKM terkait pandemi covid 19 seperti : 1) Penurunan permintaan ; 2) Kelangkaan bahan baku ; 3) Persediaan barang berlebih ; 4) Fluktuasi harga ; 5) Perubahan perilaku konsumen ; 6) Kelangkaan tenaga kerja. Permasalahan tersebut akan terus bertambah parah karena pandemi covid 19 belum diketahui kapan akan berakhir ditambah lagi adanya PPKM darurat. Di tengah tantangan yang cukup berat ini para pelaku UMKM harus jeli menangkap peluang yang ada dengan melek literasi keuangan dan melek literasi digital. Berbagai permasalahan di atas dapat dihadapi jika para pelaku UMKM mampu merubah tantangan menjadi peluang usaha baru sebagai penggerak pemulihan ekonomi.

Berdasarkan uraian di atas rumusan masalah penelitian sebagai berikut : Bagaimanakah pengaruh literasi 
keuangan dan literasi digital UMKM kuliner kota Padang terhadap omset secara parsial dan simultan sebagai penggerak pemulihan ekonomi masa pandemi covid 19. Tujuan penelitian mengetahui pengaruh literasi keuangan dan literasi digital UMKM kuliner kota Padang terhadap omset secara parsial dan simultan sebagai penggerak pemulihan ekonomi masa pandemi covid 19. Klasifikasi UMKM(Tambunan, 2012) sbb :livelhood activities, micro enterprise, small dynamic enterprise dan fast moving enterprise. Tujuan yang ingin dicapai untuk mewujudkan UMKM yang tangguh, mandiri, mampu berdaya saing dan mengambil peran utama dalam proses produksi maupun distribusi yang terkait dengan kebutuhan pokok, bahan baku dan permodalan untuk menghadapi pasar global (UU No. 20 tahun 2008). UMKM memiliki peran penting karena memiliki beberapa keunggulan sbb : 1) Mampu mengembangkan produk dengan inovasi dan teknologi ; 2) Memiliki hubungan humanisme yang erat terutama dalam usaha berskala kecil ; 3) Mampu menyerap tenaga kerja dalam jumlah besar ; 4) Mampu beradaptasi dengan cepat dan fleksibel terhadap perubahan yang terjadi terutama terkait aturan dan birokrasi ; 5) Adanya peran kewirausahaan dan dinamisasi manajerial(Partomo \& Soejoedono, 2004)

UMKM memiliki peran sangat strategis dilihat dari sudut pandang kesempatan pekerjaan, pengangguran, sumber pendapatan dan pengentasan kemiskinan (Tambunan, 2012). UMKM dikelompokkan atas 3 jenis sbb : 1) Usaha mikro jumlah karyawan 10 orang, 2) Usaha kecil jumlah karyawan 30 orang, 3) Usaha menengah jumlah karyawan lebih 30 orang (BPS, 2018). Dalam perspektif usaha UMKM diklasifikasikan atassbb : 1) UMKM sektor informal, 2) UMKM mikro, 3)
Usaha kecil dinamis, 4) Fast moving enterprise. Kriteria UMKM berdasarkan aset dan omset dapat dilihat pada tabel 2.

Tabel 2

Kriteria UMKM dan Usaha Besar Berdasarkan Aset dan Omset

\begin{tabular}{lll}
\hline \multicolumn{1}{c}{$\begin{array}{c}\text { Ukuran } \\
\text { Usaha }\end{array}$} & \multicolumn{1}{c}{ Asiteria } \\
\cline { 2 - 3 } $\begin{array}{lll}\text { Usaha } \\
\text { mikro }\end{array}$ & \multicolumn{1}{c}{ Maksimal Rp 50 juta } & \multicolumn{1}{c}{ Omset } \\
Usaha kecil & $>$ Rp 50 juta - Rp 500 & $>$ Rp 300 juta - Rp 2.5 \\
& juta & milyar \\
Usaha & $>$ Rp 500 juta - Rp 10 & $>$ Rp2,5 milyar - Rp \\
menengah & milyar & 50 milyar \\
Usaha & $>$ Rp 10 milyar & $>$ Rp 50 milyar \\
besar & & \\
\hline
\end{tabular}

Sumber : BPS, 2018

Omset adalah akumulasi kegiatan penjualan suatu produk barang/jasa dihitung secara keseluruhan selama kurun waktu tertentu secara kontinu atau dalam satu proses akuntansi dengan tujuan untuk mencapai volume penjualan tertentu, mendapatkan laba dan menunjang pertumbuhan perusahaan (Swastha, 1993). Omset penjualan adalah banyaknya barang yang diterima pembeli dengan jumlah uang yang diserahkan kepada penjual sesuai kesepakatan bersama. Menurut (Swastha dan Irawan, 1990) dalam kegiatan penjualan omset dipengaruhi oleh beberapa faktor sbb : 1) Kondisi dan kemampuan penjual ; 2) Kondisi pasar ; 3) Modal ; 4) Kondisi organisasi perusahaan ; 5) Faktor lain seperti iklan, kampanye, diskon dan pemberian hadiah. Menurut (Forsyth, 1990) dalam kegiatan penjualan sebuah produk/jasa pasti terjadi fluktuasi dipengaruhi oleh faktor internal dan faktor eksternal. Keberlanjutan usaha UMKM dilihat dari keberhasilan perusahaan dalam inovasi, pengelolaan karyawan dan pelanggan serta pengembalian terhadap modal awal (Hudson, Smart \& Bourne, 2001).

Menurut UU No.20 tahun 2008 berdasarkan aspek komoditas yang dihasilkan, UMKM memiliki karakteristik tersendiri sbb : 1) Kualitas belum standar, 2) Desain produk terbatas, 3) Jenis produk terbatas, 4) Kapasitas dan 
harga produk terbatas, 5) Bahan baku kurang standar, 6) Kontinuitas produk tidak terjamin dan kurang sempurna. Peran aspek lingkungan strategis UMKM dalam perekonomian Indonesiaseperti tabel 3 .

Tabel 3

Aspek Lingkungan Strategis

\begin{tabular}{|c|c|c|}
\hline Aspek Politik & Aspek Ekonomi & Aspek Sosial \\
\hline $\begin{array}{l}\text { Pesatnya } \\
\text { kerjasama } \\
\text { ekonomi antar } \\
\text { negara } \\
\text { terutama } \\
\text { dalam konteks } \\
\text { ASEAN dan } \\
\text { APEC yang akan } \\
\text { menciptakan } \\
\text { peluang baru } \\
\text { bagi UMKM }\end{array}$ & $\begin{array}{l}\text { 1. Kontribusi UMKM } \\
\text { terhadap } \\
\text { pembentukan PDB } \\
\text { 2. Pengembangan } \\
\text { UMKM hanya } \\
\text { butuh tingkat } \\
\text { investasi lebih } \\
\text { rendah }\end{array}$ & $\begin{array}{l}\text { 1. Sektor UMKM } \\
\text { lebih menjamin } \\
\text { stabilitas pasar } \\
\text { tenaga kerja } \\
\text { 2. Penekanan } \\
\text { pengangguran } \\
\text { jadi wahana } \\
\text { bangkitnya } \\
\text { wirausaha baru }\end{array}$ \\
\hline
\end{tabular}

Sumber :Kementerian Koperasi dan UMKM, 2016

Literasi keuangan adalah pengetahuan dan kecakapan untuk mengaplikasikan pemahaman tentang konsep dan resiko, keterampilan agar dapat membuat keputusan efektif dalam konteks keuangan untuk meningkatkan kesejahteraan keuangan, individu, sosial dan dapat berpartisipasi di lingkungan masyarakat (World Economic Forum, 2015). Literasi keuangan mutlak diperlukan oleh setiap individu agar dapat memanfaatkan instrumen maupun produk keuangan secara optimal guna mengambil keputusan secara tepat untuk kesejahteraannya. Literasi keuangan merupakan rangkaian proses/kegiatan untuk meningkatkan pengetahuan, kepercayaan dan kemampuan konsumen/masyarakat umum agar dapat mengelola keuangan dengan baik (OJK, 2013). Literasi keuangan pada orang dewasa usia 15 tahun pengetahuan dan pemahaman tentang konsep dan resiko keuangan serta keterampilan, motivasi, kepercayaan diri untuk membuat keputusan keuangan efektif guna meningkatkan kesejahteraan keuangan individu/masyarakat serta berpartisipasi di kegiatan ekonomi (OECD, 2014 \& 2016). Literasi keuangan pada mahasiswa merupakan pengetahuan untuk pengelolaan keuangan dalam pengambilan keputusan (Chen dan Volpe, 1998). Literasi keuangan sebagai kombinasi kesadaran, pemahaman, pengetahuan dan penggunaan konsepkonsep keuangan untuk membuat keputusan keuangan (Opoku, 2015).

Seseorang well literate memiliki pengetahuan dan keyakinan tentang lembaga, produk dan layanan jasa keuangan serta keterampilan dalam mengetahui fitur, manfaat, resiko, hak dan kewajiban dari produk dan layanan jasa keuangan (OJK, 2013). Literasi keuangan merupakan pengukuran terhadap pemahaman seseorang tentang konsep keuangan, memiliki kemampuan terhadap instrumen keuangan dan keyakinan untuk mengatur keuangan pribadi melalui pengambilan keputusan jangka pendek dan aplikasinya dalam bisnis dan kehidupan untuk perencanaan keuangan (Remund \& Huston 2010). Dimensi literasi keuangan yakni keterampilan menghitung, pemahaman tentang keuangan dasar dan sikap terhadap keputusan keuangan. Menurut (Carpena et all, 2011) dimensinya terdiri dari pengetahuan dan konteks literasi keuangan meliputi pengetahuan, edukasi dan informasi tentang keuangan dan sumbernya kemudian (Willis, 2008) terdiri dari perbankan, deposito, kredit, asuransi dan pajak.

Pengetahuan keuangan yang dimiliki seseorang akan berkembang menjadi keterampilan keuangan sebagai kemampuan dalam menerapkan pengetahuan keuangan yang dimilikinya dalam kehidupan sehari-hari (Palameta, et al, 2016) sehingga memungkinkan seseorang untuk mengambil keputusan rasional dan efektif terkait dengan keuangan dan sumber ekonominya (Kurihara, 2013). Masyarakat diharapkan memiliki keyakinan terhadap lembaga jasa keuangan serta produk dan 
layanannya setelah memiliki pengetahuan dan keterampilan yang memadai juga yakin dalam melaksanakan aktivitas keuangan (Tustin, 2016). Peningkatan pengetahuan, keterampilan dan keyakinan keuangan yang dimiliki seorang individu berpengaruh terhadap sikap dan perilaku keuangan yang lebih baik pada seorang individu untuk jangka panjang dibandingkan dengan seseorang yang memiliki sikap keuangan untuk jangka pendek (Atkinson \& Messy, 2012). Indikator literasi keuangan (World Bank, 2016) sbb : 1) Terencana dan terukur ; 2) Berorientasi pada pencapaian ; 3) Berkelanjutan ; 4) Kolaborasi. Tingkatan literasi keuangan (OJK, 2013) sbb : 1) Well literate; 2) Sufficient literate; 3) Less literate; 4) Not literate (OJK, 2013). Indikator literasi keuangan (INFE, 2012) sbb: 1) Pengetahuan keuangan ; 2) Perilaku keuangan ; 3) Sikap. Indikator literasi keuangan (Wagland \& Taylor, 2009) tentang konsep dasar keuangan seperti tingkat bunga majemuk, tingkat bunga sederhana, inflasi ; (Samuelson dan Nordhaus, 2001) tentang tabungan, pinjaman dan investasi ; Sawitri \& Hartono, 2007) tentang asuransi sebagai pengalihan dan pengelolaan resiko dari nasabah dimana nasabah bersedia membayar premi yang dikelola oleh pihak perusahaan asuransi (www : https//ojk.go.id). Program yang digunakan dalam meningkatkan indeks literasi keuangan (Suryani, 2015) sbb : 1) Meningkatkan literasi seseorang yang sebelumnya less literate/not literate menjadi well literate ; 2) Infrastruktur literasi keuangan ; 3) Pengembangan produk dan jasa keuangan. Literasi keuangan bermanfaat cukup besar bagi masing-masing individu, lembaga jasa keuangan dan negara untuk meningkatkan pertumbuhan ekonomi, mengentaskan kemiskinan, mengurangi ketimpangan pendapatan dan meningkatkan stabilitas sistem keuangan (Sotiono, 2018).

Literasi digital menjelaskan tentang konsep di era digital (Bawden, 2001) sebagai kemampuan untuk memahami dan menggunakan berbagai informasi melalui piranti komputer (Gilster, 1997). Literasi digital tidak hanya kemampuan teknis mengoperasikan komputer sebagai peralatan digital tapi juga kemampuan beradaptasi dengan aktifitas yang termediasi teknologi digital termasuk praktek sosial. (Jones \& Hafner, 2012). Elemen essensial indikator untuk mengembangkan literasi digital (Bershaw, 2011) sbb : 1) Kultural ; 2) Kognitif ; 3) Konstruktif ; 4) Komunikatif ; 5) Kepercayaan ; 6) Kreatif ; 7) Bertanggung jawab secara sosial.

Aspek kultural menjadi elemen terpenting karena memahami konteks pengguna akan membantu aspek kognitif dalam menilai konten (Belshaw, 2011).

Konsep literasi digital sebagai landasan penting untuk memahami perangkat teknologi, informasi, komunikasi dan konsep literasi digital sejalan dengan terminologi yang dikembangkan oleh (UNESCO, 2011) merujuk kepada kegiatan literasi sehingga merupakan life skill. Prinsip dasar pengembangan literasi digital sbb : 1) Pemahaman; 2) Saling ketergantungan ; 3) Faktor sosial ; 4) Kurasi. Pendekatan yang dapat dilakukan pada literasi digital mencakup pendekatan konseptual dan operasional. Pendekatan konseptual fokus pada aspek perkembangan kognitif dan sosial emosional sedangkan pendekatan operasional fokus pada kemampuan teknis penggunaan media itu sendiri. Prinsip pengembangan literasi digital (Mayes dan Fowler, 2006) tingkatannya sbb : 1) Kompetensi digital ; 2) Penggunaan digital ; 3) Transformasi digital

Literasi digital bertujuan menggunakan media digital secara bertanggung jawab, 
mengetahui aspek dan konsekuensi hukum terkait UU No. 19 tahun 2019 tentang Informasi dan Transaksi Elektronik. Literasi keuangan berbasis masyarakat (Kemendikbud, 2017) terdiri dari : 1) Jumlah sarana dan prasarana yang mendukung literasi digital ; 2) Tingkat keterlibatan komunitas dan lembaga dalam pengembangan literasi digital dengan indikatornya sbb :

1. Meningkatnya jumlah dan variasi bacaan literasi digital yang dimiliki setiap fasilitas publik

2. Meningkatnya frekuensi membaca bahan bacaan literasi digital setiap hari ;

3. Meningkatnya jumlah bahan bacaan literasi digital yang dibaca oleh masyarakat setiap hari

4. Meningkatnya jumlah partisipasi aktif komunitas, lembaga atau instansi dalam penyediaan bahan bahan literasi digital ;

5. Meningkatnya jumlah fasilitas publik yang mendukungliterasi digital ;

6. Meningkatnya jumlah kegiatan literasi digital yang ada di dalam masyarakat ;

7. Meningkatnya partisipasi aktif masyarakat dalam kegiatan literasi digital ;

8. Meningkatnya pelatihan literasi digital yang aplikatif dan berdampak pada masyarakat

9. Meningkatnya pemanfaatan media digital dan internet dalam memberikan akses informasi dan layanan publik

10. Meningkatnya pemahaman masyarakat terkait penggunaan internet dan UU ITE

11. Meningkatnya angka ketersediaan akses dan pengguna (melek) internet di suatu daerah

12. Meningkatnya jumlah pelatihan literasi digital yang aplikatif dan berdampak pada masyarakat

\section{Kerangka Pemikiran}

Kebijakan pemerintah tentang pajak UMKM $0,5 \%$ per tahun, bantuan pembiayaan kredit mikro dan penangguhan pembayaran kredit selama 6 bulan saat pandemi covid 19 ternyata belum cukup efektif untuk Pemulihan Ekonomi Nasional (PEN) di era ekonomi digital karena para pelaku UMKM terkendala dengan literasi keuangan dan literasi digital karena minimnya informasi tentang literasi keuangan dan literasi digital para pelaku UMKM sehingga akan berdampak terhadap rantai bisnis UMKM dan perluasan lapangan kerja dalam jangka panjang. Kerangka pemikiran penelitian dapat dilihat pada gambar 1.

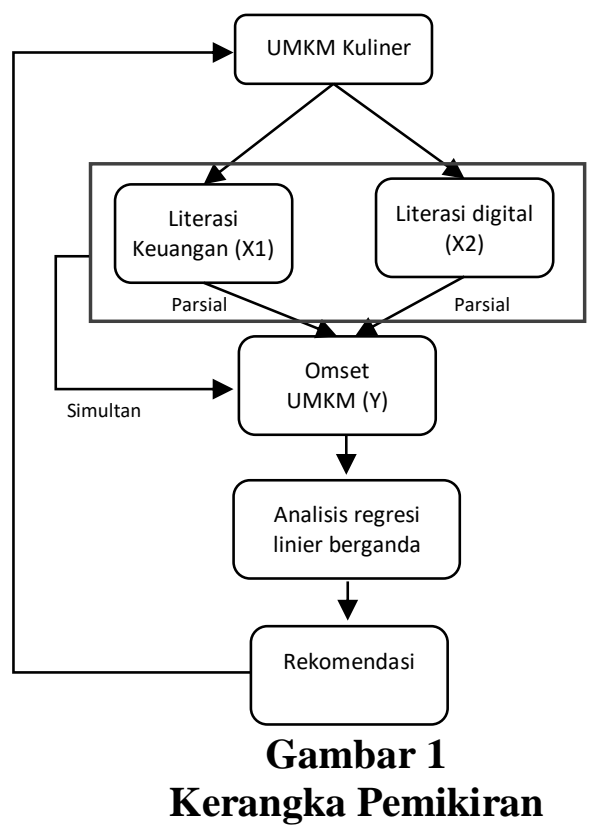

Hipotesis penelitian merupakan jawaban sementara yang harus dibuktikan kebenarannya (Sekaran, 2006). Hipotesis alternatif pertama $\left(\mathrm{HA}_{1}\right)$ diduga literasi keuangan berpengaruh positif signifikan terhadap omset UMKM kuliner kota Padang. Hipotesis alternatif kedua $\left(\mathrm{HA}_{2}\right)$ diduga literasi digital berpengaruh positif 
signifikan terhadap omset UMKM kuliner kota Padang. Hipotesis alternatif ketiga $\left(\mathrm{HA}_{3}\right)$ diduga literasi keuangan dan literasi digital berpengaruh positif signifikan terhadap omset UMKM kuliner kota Padang. Hipotesis penelitian dapat dilihat pada gambar 2 .

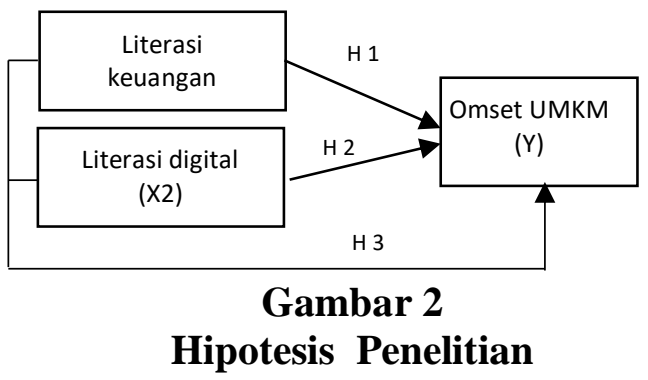

\section{METODE PENELITIAN}

Jenis penelitian asosiatif bertujuan memberi gambaran jelas tentang masalah penelitian dengan pendekatan kuantitatif sebagai proses menemukan pengetahuan memakai data berupa angka sebagai alat analisis keterangan tentang apa yang ingin diketahui (Uma, 2015). Populasi penelitian merupakan wilayah generalisasi terdiri atas objek / subjek dengan kausalitas dan karakteristik yang ditetapkan oleh peneliti untuk dipelajari dan ditarik kesimpulan (Umar, 2015) sehingga setiap data dapat dinyatakan dengan tepat (Sugiyono, 2015). Populasi penelitian 371 buah UMKM jenis Industri Makanan Ringan (IMR) di kecamatan Padang Barat kota Padang dan sampel 193 UMKM jenis IMR ditentukan dengan rumus Slovin pada $\alpha=$ $5 \%$ secara purposive sampling.Data penelitian berupa dataprimer diperoleh dari angket dan data sekunder diperoleh melalui library research.

Variabel penelitian merupakan instrumen penelitian menghubungkan konsep dengan fakta empiris dengan pemberian bilangan (simbol) menurut aturan berlaku (Umar, 2015) dengan definisi operasional variabel penelitiannyaseperti tabel 4 .
Tabel 4

Definisi Operasional Variabel Penelitian

\begin{tabular}{|c|c|}
\hline $\begin{array}{c}\text { Definisi Operasional Variabel } \\
\text { Penelitian }\end{array}$ & Indikator \\
\hline $\begin{array}{l}\text { Omset }(\mathrm{Y}) \text { adalah kenaikan } \\
\text { pendapatan kapasitas produksi }\end{array}$ & $\begin{array}{l}\text { 1. Pertumbuhan penjualan } \\
\text { 2. Pertumbuhan modal } \\
\text { 3. Pertumbuhan tenaga kerja } \\
\text { 4. Pertumbuhan pasar } \\
\text { 5. Pertumbuhan laba / laba } \\
\text { usaha }\end{array}$ \\
\hline $\begin{array}{l}\text { Literasi keuangan }\left(\mathrm{X}_{1}\right) \text { adalah } \\
\text { rangkaian proses/kegiatan untuk } \\
\text { meningkatkan pengetahuan, } \\
\text { kepercayaan dan kemampuan } \\
\text { konsumen/masyarakat umum } \\
\text { agar dapat mengelola keuangan } \\
\text { dengan baik. }\end{array}$ & $\begin{array}{l}\text { 1. Pengetahuan umum } \\
\text { keuangan } \\
\text { 2. Perilaku keuangan } \\
\text { 3. Tabungan dan pinjaman } \\
\text { 4. Asuransi } \\
\text { 5. Investasi }\end{array}$ \\
\hline $\begin{array}{l}\text { Literasi digital }\left(\mathrm{X}_{2}\right) \text { adalah } \\
\text { pengetahuan dan kecakapan } \\
\text { menggunakan media digital, } \\
\text { alat-alat, komunikasi atau } \\
\text { jaringan dalam menemukan, } \\
\text { mengevaluasi, menggunakan, } \\
\text { membuat informasi dan } \\
\text { memanfaatkannya }\end{array}$ & $\begin{array}{l}\text { 1. Kultural } \\
\text { 1. Kognitif } \\
\text { 2. Konstruktif } \\
\text { 3. Komunikatif } \\
\text { 4. Percaya diri } \\
\text { 5. Kreatif } \\
\text { 6. Bertanggung jawab }\end{array}$ \\
\hline
\end{tabular}

Pengumpulan data merupakan cara yang dibutuhkan untuk menjawab rumusan masalah dengan teknik sbb:1) Wawancara dengan sampel dan pihak terkait, 2) Observasi langsung ke sampel, 3) Memberikan angket kepada sampel karena angket dapat mengumpulkan informasi lebih banyak dalam waktu relatif singkat (Yusuf, 2014). Tanggapan responden terhadap variabel penelitian menggunakan skala Likert skor $1-5$ (Umar, 2015) dengan alternatif jawaban sbb : Sangat Tidak Baik (STB) skor 1, Tidak Baik (TB) skor 2, Cukup Baik (CB) skor 3, Baik (B) skor 4 dan Sangat Baik (SB) skor 5 dengan cara editing, skoring dan tabulasi (Umar, 2015). Sebelum data dianalisis terlebih dahulu dilakukan uji instrumen dan uji asumsi klasik (Ghozali, 2006). Analisis data menggunakan regresi linier berganda dengan formula $Y$ $=\mathrm{a}+\mathrm{b}_{1} \mathrm{X}_{1}+\mathrm{b}_{2} \mathrm{X}_{2}+\mathrm{e}$ dimana $\mathrm{a}=$ konstanta, $\mathrm{Y}=$ omset, $\mathrm{X}_{1}=$ literasi keuangan, $\mathrm{X}_{2}=$ literasi digital, $\mathrm{b}_{1}=\mathrm{b}_{2}=$ koefisien regresi variable bebas dan $\mathrm{e}=$ kesalahan penganggu. Uji hipotesis 
menggunakan $\quad \alpha=5 \%$ secara parsial ketentuannya jika $\mathrm{t}$ hitung $\geq \mathrm{t}$ tabel maka hipotesis diterima sebaliknya jika t hitung $<\mathrm{t}$ tabel maka hipotesis ditolak.Uji hipotesis secara simultan ketentuannya jika $\mathrm{F}$ hitung $\geq \mathrm{F}$ tabel maka hipotesis diterima sebaliknya jika $\mathrm{F}$ hitung < $\mathrm{F}$ tabel maka hipotesis ditolak. Uji hipotesis secara parsial dan simultan bisa juga menggunakan nilai $p$ value $0,000<0,05$ berarti signifikan sebaliknya nilai $p$ value $0,000>0,05$ berarti tidak signifikan. Hasil analisis data juga menunjukkan nilai Koefisien Determinasi (KD) dan Adjusted $R \quad$ Squareinterpretasi nilaiAdjusted RSquare 0 - 1 (Ghozali, 2006).

\section{HASIL DAN PEMBAHASAN}

UMKM terdiri berbagai jenis Industri Makanan Ringan (IMR) pada umumnya merupakan usaha kuliner yang menyajikan berbagai makan dan minuman kepada para konsumen. Karakteristik responden yang mengelola atau sebagai pemilik UMKM terdiri dari laki-laki dan perempuan

responden dalam penelitian ini paling banyak perempuan 102 orang $(52,85 \%)$ sisanya laki-laki 91 orang $(47,15 \%)$.. Pemilik UMKM usianya bervariasi seperti pada tabel 5 .

\section{Tabel 5}

Karakteristik Responden Berdasarkan Usia

\begin{tabular}{cccc}
\hline No. & $\begin{array}{c}\text { Rentang Usia } \\
\text { (Tahun) }\end{array}$ & Jumlah (Orang) & Persentase (\%) \\
\hline 1. & $\leq 20$ tahun & 18 & 9,33 \\
2. & $21-30$ tahun & 53 & 27,46 \\
3. & $31-40$ tahun & 77 & 39,90 \\
4. & $\geq 41$ tahun & 45 & 23,32 \\
\hline & Jumlah & 193 & 100 \\
\hline
\end{tabular}

Sumber : Data Primer Diolah, 2021

Berdasarkan tabel 5 diketahui paling banyak pemilik usaha/pengelola
UMKM usia 31 - 40 tahun 77 orang $(39,90 \%)$. Karakteristk responden berdasarkan jenjang pendidikan dapat dilihat pada tabel 6 .

Tabel 6

Karakteristik Responden Berdasarkan Pendidikan

\begin{tabular}{clcc}
\hline $\mathrm{b}$ & Rentang Usia (Tahun) & $\begin{array}{c}\text { Jumlah } \\
\text { (Orang) }\end{array}$ & Persentase (\%) \\
\hline 1. & Tamat SD / MI & 19 & 9,84 \\
2. & Tamat SMP / MTS & 33 & 17,10 \\
3. & SMA/SMK/MA & 111 & 57,51 \\
4. & Diploma/Sarjana & 30 & 15,54 \\
\hline & Jumlah & $\mathbf{1 9 3}$ & $\mathbf{1 0 0}$
\end{tabular}

Sumber : Data Primer Diolah, 2021

Jenjang pendidikan yang ditamatkan paling banyak SMA/SMK/MA 111 orang $(57,51 \%)$ berdasarkan tabel 6 . Hal ini terjadi karena kebanyakan responden tidak mau melanjutkan jenjang pendidikan lebih tinggi, lebih baik langsung bekerja pada sektor formal yang dapat menghasilkan uang langsung sebagai pekerja. Karakteristik responden berdasarkan pekerjaan dapat dilihat pada tabel 7.

Tabel 7

Karakteristik Responden Berdasarkan Pekerjaan

\begin{tabular}{|c|c|c|c|}
\hline No. & Jenis Pekerjaan & $\begin{array}{l}\text { Jumlah } \\
\text { (Orang) }\end{array}$ & Persentase (\%) \\
\hline 1. & Mahasiswa & 22 & 11,40 \\
\hline 2. & Wiraswasta & 103 & 53,37 \\
\hline 3. & PNS & 17 & 8,81 \\
\hline \multirow[t]{2}{*}{4.} & Lain-lain & 51 & 26,42 \\
\hline & Jumlah & 193 & 100 \\
\hline
\end{tabular}

Sumber : Data Primer Diolah, 2021

Tabel 7 di atas menunjukkan pekerjaan responden paling banyak sebagai wiraswasta 103 orang $(53,37 \%)$. Hal ini terjadi karena penghasilan dapat menghasilkan uang lansung sebagai wiraswasta dan lain-lainnya sebagai buruh 51 orang $(26,42 \%)$.

Hasil uji validitas seperti tabel 8 berikut : 
Tabel 8

Hasil Uji Validitas

\begin{tabular}{|c|c|c|c|c|}
\hline No. & Pernyataan & $r$ hitung & $r$ tabel & Keterangan \\
\hline & Omset $(\mathrm{Y})$ & & & \\
\hline 1. & Indikator 1 & 0,368 & 0,30 & Valid \\
\hline 2. & Indikator 1 & 0,473 & 0,30 & Valid \\
\hline 3. & Indikator 2 & 0,352 & 0,30 & Valid \\
\hline 4. & Indikator 2 & 0,406 & 0,30 & Valid \\
\hline 5. & Indikator 3 & 0,726 & 0,30 & Valid \\
\hline 6. & Indikator 3 & 0,683 & 0,30 & Valid \\
\hline 7. & Indikator 4 & 0,577 & 0,30 & Valid \\
\hline 8. & Indikator 4 & 0,458 & 0,30 & Valid \\
\hline 9. & Indikator 5 & 0,336 & 0,30 & Valid \\
\hline \multirow[t]{2}{*}{10.} & Indikator 5 & 0,365 & 0,30 & Valid \\
\hline & $\begin{array}{l}\text { Literasi } \\
\text { Keuangan } \\
\left(\mathrm{X}_{1}\right)\end{array}$ & & & \\
\hline 1. & Indikator 1 & 0,533 & 0,30 & Valid \\
\hline 2. & Indikator 1 & 0,617 & 0,30 & Valid \\
\hline 3. & Indikator 2 & 0,449 & 0,30 & Valid \\
\hline 4. & Indikator 2 & 0,473 & 0,30 & Valid \\
\hline 5. & Indikator 3 & 0,536 & 0,30 & Valid \\
\hline 6. & Indikator 3 & 0,479 & 0,30 & Valid \\
\hline 7. & Indikator 4 & 0,631 & 0,30 & Valid \\
\hline 8. & Indikator 4 & 0,679 & 0,30 & Valid \\
\hline 9. & Indikator 5 & 0,773 & 0,30 & Valid \\
\hline \multirow[t]{2}{*}{10.} & Indikator 5 & 0,687 & 0,30 & Valid \\
\hline & $\begin{array}{l}\text { Literasi } \\
\text { Digital }\left(\mathrm{X}_{2}\right)\end{array}$ & & & \\
\hline 1. & Indikator 1 & 0,335 & 0,30 & Valid \\
\hline 2. & Indikator 1 & 0,419 & 0,30 & Valid \\
\hline 3. & Indikator 2 & 0,632 & 0,30 & Valid \\
\hline 4. & Indikator 2 & 0,557 & 0,30 & Valid \\
\hline 5. & Indikator 3 & 0,445 & 0,30 & Valid \\
\hline 6. & Indikator 3 & 0,564 & 0,30 & Valid \\
\hline 7. & Indikator 4 & 0,547 & 0,30 & Valid \\
\hline 8. & Indikator 4 & 0,641 & 0,30 & Valid \\
\hline 9. & Indikator 5 & 0,548 & 0,30 & Valid \\
\hline 10. & Indikator 5 & 0,485 & 0,30 & Valid \\
\hline 11. & Indikator 6 & 0,418 & 0,30 & Valid \\
\hline 12. & Indikator 6 & 0,571 & 0,30 & Valid \\
\hline 13. & Indikator 7 & 0,643 & 0,30 & Valid \\
\hline 14. & Indikator 7 & 0,632 & 0,30 & Valid \\
\hline
\end{tabular}

Sumber : Data Primer Diolah, 2021

Tabel 8 di atas menunjukkan korelasi masing-masing indikator terhadap total skor konstruk variabel omset, literasi keuangan dan literasi digital hasilnya valid karena $r$ hitung $>r$ tabel 0,30 sehingga disimpulkan semua indikator angket yang dipakai masingmasing variabel valid untuk digunakan sebagai alat ukur variabel terikat dan variabel bebas.

Uji reliabelitas merupakan uji instrumen menunjukkan seberapa besar alat ukur dapat diandalkan dalam mengukur indikator masing-masing variabel bebas dan variabel terikat penelitian seperti pada tabel 9.

\section{Tabel 9}

Hasil Uji Reliabelitas

\begin{tabular}{llccc}
\hline No. & $\begin{array}{c}\text { Variabel } \\
\text { Penelitian }\end{array}$ & $\begin{array}{c}\text { Cronbach } \\
\text { Alpha }\end{array}$ & r tabel & Keterangan \\
\hline 1. & Omset & 0.783 & 0,60 & Reliabel \\
2. & $\begin{array}{l}\text { Literasi } \\
\text { keuangan }\end{array}$ & 0.681 & 0,60 & Reliabel \\
3. & Literasi digital & 0.789 & 0,60 & Reliabel \\
\hline \multicolumn{4}{l}{ Sumber : Data Primer Diolah, 2021 }
\end{tabular}

Berdasarkan tabel 9 di atas semua variabel penelitian ternyata nilai Cronbach alpha $>0,60$ sehingga semua indikator variabel penelitian reliabel dan layak digunakan sebagai alat ukur uji instrumen penelitian.

\section{Uji Normalitas}

Uji normalitas pada penelitian ini menggunakan uji Kolmogorov Smirnov untuk pengambilan keputusan (Ghozali, 2006). Bila nilai probabilitas (Asymp.Sig) < 0,05 maka data tidak berdistribusi normal sebaliknya bila nilai probabilitas (Asymp.Sig) > 0,05 maka data berdistribusi normal. Hasil uji normalitas penelitian ini dapat dilihat pada tabel 10

Tabel 10.

Hasil Uji Normalitas - One Sampel Kolmogorov Smirnov

\begin{tabular}{llr}
\hline & & $\begin{array}{c}\text { Standardized } \\
\text { Residual }\end{array}$ \\
\hline $\mathrm{N}$ & Mean & 156 \\
Normal Parameters & Std. & .000000 \\
& Striation & .02526473 \\
Most Extreme & Devisolute & .076 \\
Differences & Positive & .069
\end{tabular}




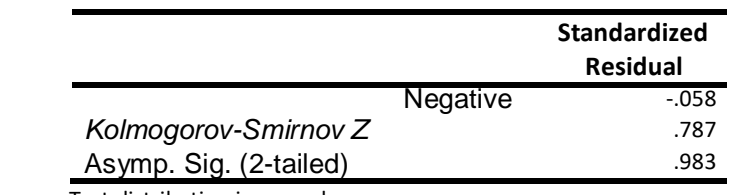

a. Test distribution is normal

Sumber : Data Primer Diolah, 2021

Hasil pengujian statistik One Sampel Kolmogorov Smirnov pada tabel di atas menunjukkan nilai Sig. sebesar 0,983 artinya nilai tersebut lebih besar dari 0,05 sehingga dapat disimpulkan bahwa nilai residual terdistribusi normal sehingga memenuhi syarat uji normalitas.

\section{Uji Multikolonieritas}

Jika multikolonieritas kurang sempurna maka nilai koefisien regresi meskipun berhingga akan mempunyai standar deviasi besar berarti nilai koefisiennya tidak dapat ditaksir dengan mudah (Ghozali, 2006).Hasil pengujian model regresi menunjukkan nilai Tolerance dan VIF seperti tabel 12.

\section{Tabel 11}

Hasil Uji Multikolonieritas

Coefficients $^{\mathrm{a}}$

\begin{tabular}{ccccl}
\hline Model & Variabel & Tolerance & VIF & Keterangan \\
\hline 1 & (Constant) & & & \\
& LTK & .694 & 2.107 & $\begin{array}{l}\text { Tidak terjadi } \\
\text { multikolonieritas } \\
\text { LTD }\end{array}$ \\
& .694 & 2.107 & $\begin{array}{l}\text { Tidak terjadi } \\
\text { multikolonieritas }\end{array}$ \\
\hline
\end{tabular}

Berdasarkan tabel 11 di atas nilai VIF untuk semua variabel bebas tidak lebih dari 10 dan nilai Tolerance mendekati 1. Hal ini menunjukkan bahwa semua variabel bebas terdiri dari literasi keuangan dan literasi digital tidak menunjukkan terjadinya multikolonieritas.

\section{Uji Autokorelasi}

Hasil uji autokorelasi dapat dilihat pada tabel 12 berikut :
Tabel 12

Hasil Uji Autokorelasi - Durbin Watson

\begin{tabular}{|c|c|c|c|c|c|}
\hline Model & $\mathrm{R}$ & $\begin{array}{c}\mathrm{R} \\
\text { Square }\end{array}$ & $\begin{array}{l}\text { Adjusted R } \\
\text { Square }\end{array}$ & $\begin{array}{l}\text { Std. Error } \\
\text { of the } \\
\text { Estimate }\end{array}$ & $\begin{array}{l}\text { Durbin- } \\
\text { Watson }\end{array}$ \\
\hline 1 & $.796^{\mathrm{a}}$ & .633 & .625 & .09858868 & 2.4604 \\
\hline
\end{tabular}

Predictors: (Constant), LTK dan LTD

Dependent Variable : OMS

Dari tabel 12 di atas diperoleh nilai uji statistik $\mathrm{DW}=2,411 \mathrm{dl}=1,3221$ $\mathrm{du}=1,5660 \quad(4-\mathrm{dl})=2,6788$ dan $(4-\mathrm{du})$ $=2,423$ sehingga nilai DW terletak antara du dan (4-du) berarti nilai DW 2,411 terletak antara nilai du dan (4-du) sebesar 1,5770 dan 2,423 (du < DW < 4-du) berarti tidak terjadi autokorelasi dalam model regresi yang digunakan dalam penelitian ini.

Tabel 13 korelasi literasi keuangan dan literasi digital dengan omset UMKM kuliner kota Padang $79,6 \%$ (kuat) dan literasi keuangan, literasi digital mampu menjelaskan omset UMKM kuliner kota Padang 62,5\% sedangkan sisanya 37,5\% dijelaskan oleh faktor lain yang tidak masuk ke dalam model penelitian.

\section{Uji Heteroskedastisitas}

Uji heteroskedastistas menggunakan uji koefisien korelasi Rank Spearman yaitu mengkorelasikan absolut residual hasil regresi dengan semua variabel bebas. Bila signifikansi hasil korelasi lebih kecil daripada 0,05 maka pada persamaan regresi terjadi heteroskedastisitas sebaliknya tidak terjadi heteroskedastisitas atau homoskedastisitas. Hasil uji heteroskedastisitas ddapat dilihat pada tabel 13 berikut : 
Tabel 13

Hasil Uji Heteroskedastisitas Correlations

\begin{tabular}{|c|c|c|c|}
\hline & & & Abs \\
\hline \multirow[t]{2}{*}{$\begin{array}{l}\text { Spearman's } \\
\text { rho }\end{array}$} & LTK & $\begin{array}{l}\text { Correlation Coefficient } \\
\text { Sig. (2-tailed) } \\
\mathrm{N}\end{array}$ & $\begin{array}{l}.212 \\
.165 \\
193\end{array}$ \\
\hline & LTD & $\begin{array}{l}\text { Correlation Coefficient } \\
\text { Sig. (2-tailed) } \\
\mathrm{N}\end{array}$ & $\begin{array}{l}.297 \\
.281 \\
193\end{array}$ \\
\hline & Abs & $\begin{array}{l}\text { Correlation Coefficient } \\
\text { Sig. ( 2-tailed } \\
\text { N }\end{array}$ & $\begin{array}{r}1.000 \\
193\end{array}$ \\
\hline
\end{tabular}

Correlation is significant at the 0.01 level (2tailed)

Berdasarkan tabel 13 di atas semua variabel bebas penelitian nilai Sig. (2-tailed) lebih besar daripada 0,05 dapat disimpulkan bahwa variabel yang diuji tidak terjadi heteroskedastisitas artinya tidak ada korelasi antara besar data dengan residual sehingga bila diperbesar tidak menyebabkan residual (kesalahan) semakin besar.

Hasil olahan data pengaruh literasi keuangan dan literasi digital terhadap omset UMKM kuliner kota Padang dapat dilihat pada tabel 14 .

\section{Tabel 14}

Coefficients $^{\mathrm{a}}$

\begin{tabular}{|c|c|c|c|c|c|}
\hline \multirow[t]{2}{*}{ Model } & \multicolumn{2}{|c|}{$\begin{array}{l}\text { Unstandarized } \\
\text { Coefficients }\end{array}$} & \multirow{2}{*}{$\begin{array}{l}\text { Standardized } \\
\text { Coefficients } \\
\text { Beta }\end{array}$} & \multirow[t]{2}{*}{$\mathbf{t}$} & \multirow[t]{2}{*}{ Sig. } \\
\hline & B & Std. Error & & & \\
\hline 1 (Constant) & 1.657 & 137.160 .018 & .425 & 9.679 & .000 \\
\hline $\begin{array}{l}\text { Literasi } \\
\text { keuangan }\end{array}$ & .539 & .153 .274 .170 & .573 & .685 & .000 \\
\hline $\begin{array}{l}\text { Literasi } \\
\text { digital }\end{array}$ & .723 & 114.305 .219 & .742 & .713 & .007 \\
\hline
\end{tabular}

Berdasarkan tabel 14 didapat persamaan regresi linier berganda $\mathrm{Y}=$ $1.657+0.539 \mathrm{X}_{1}+0.723 \mathrm{X}_{2}+\mathrm{e}$ dengan interpretasinya sebagai berikut :

1. $\mathrm{a}=1.657$ artinya jika literasi keuangan dan literasi digitalnol persen maka omset UMKM kuliner sebesar 1.657persen.

2. $\mathrm{b}_{1}=0.539$ artinya jika literasi keuangan naik satu persen maka omset UMKM kuliner naik sebesar 0.539 persen dengan asumsi literasi digital ceteris paribus.
3. $b_{2}=0.723$ artinya jika literasi digital naik satu persen maka omset UMKM kuliner naik sebesar 0.723 persen dengan asumsi literasi keuangan ceteris paribus.

Uji parsial pada tabel 15 menunjukkan bahwa variabel bebas literasi keuangan dan literasi digital berpengaruh positif signifikan secara parsialterhadap omset UMKM kuliner kota Padang.

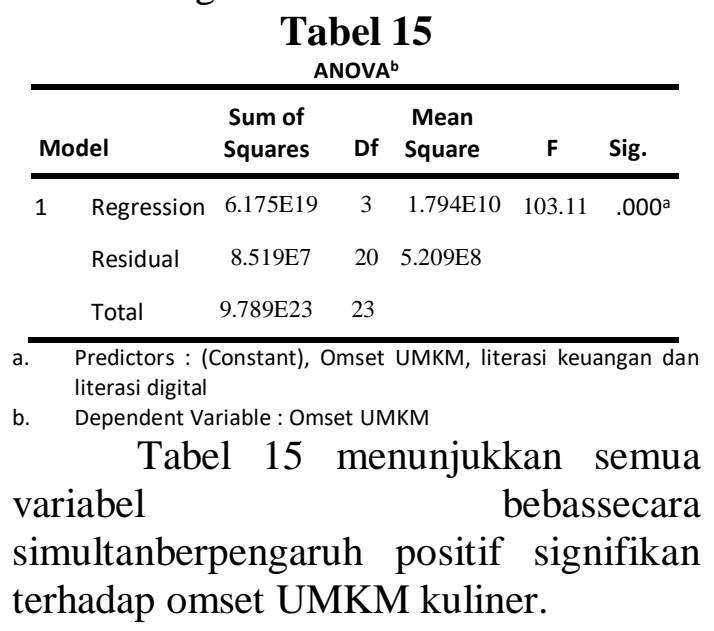

\section{SIMPULAN}

Berdasarkan hasil pembahasan penelitian di atas dapat diambil kesimpulan sbb :

1. Didapat persamaan regresi linier bergandaY $=1.657+0,539 \mathrm{X}_{1}+$ $0,723 \mathrm{X}_{2}$ memenunjukkan variabel bebas literasi keuangan lebih kecil pengaruhnya daripada literasi digital terhadap omset UMKMkuliner kota Padang. Secara parsial dan simultan semua variabel bebas penelitian berpengaruh positif signifikan terhadap omset UMKM kuliner kota Padang.

2. Nilai koefisien korelasi $r=0,796$ berarti literasi keuangan dan literasi digitalhubungannya kuat dengan omset UMKM kuliner kota Padang.

3. Nilai Adjusted $R$ Square $=0,625$ berarti omset UMKMkuliner kota Padang mampu dijelaskan oleh literasi keuangan dan literasi digital $62.5 \%$ sisanya $37,5 \%$ dipengaruhi oleh faktor 
lain yang tidak termasuk dalam model penelitian.

Saran yang dapat diberikan sesuai dengan kesimpulan di atas sebagai berikut :

1. UMKMkuliner kota Padang hendaknya dapat lebih meningkatkan omsetnya dengan melakukan berbagai inovasi produk menggunakan berbagai dana Bantuan Langsung Tunai (BLT) saat pandemi covid 19 .

2. Kepada peneliti selanjutnya agar dapat meneliti faktor-faktor lain yang mempengaruhi omset UMKM kuliner secara mikro dan makro saat pandemi covid 19.

3. Kepada peneliti selanjutnya agar dapat menambah jumlah sampel penelitian sehingga hasil penelitian diharapkan tidak bias.

\section{DAFTAR PUSTAKA}

Adda, Godfrey. 2020. Financial Management Practices and Growth of Small and MediumScale Enterprises : The Case of Kassena-Nankana West District. Research in Business and Management. 7(2) : $39-50$.

Atkinson, P \& Hammersley, M. 2009. Ethnography and Participant Observation. London :Sage.

Badan Pusat Statistik. 2018. Laporan Perekonomian Indonesia 2017.Jakarta : BPS Statistik Indonesia.

Bank Indonesia. 2021. Bersinergi Membangun Optimisme Pemulihan Ekonomi. Laporan Perekonomian Indonesia Tahun 2020. Jakarta : Departemen Kebijakan Ekonomi dan Moneter. Bawden, D. 2001. Information and Digital Literacies : A Review of Concept. Journal of Documentation. 57(2) : 218-259.

Boon, T, Yee, H \& Ting, H. 2011. Financial Literacy and Personal
Financial Planning in Klang Valley Malaysia. International Journal of Economics and Management. 5(1) :

149 - 168. Diakses dari http://econ.upm.edu.my/ijem/vol 5no1/bab08.pdf

Buletin Pos dan Telekomunikasi. 2016. 14(1) : $79-94$.

Carpena, F, Cole, S, Shapiro, J \& Zia, B. 2011. Unpacking the Causal Chain of Financial

Literacy. WashingtonD.C. Financial Literacy. Washington D.C. The World Bank.

Chen,K \& Volpe, R.P. 1998. An Analysis of Personal Financial Literacy Among College

Students. Financial Services Review 7(2) : $107-128$.

Chinen, K \& Endo, H. 2014. Observation of Financial Literacy Among the Selected Student in the U.S and Japan. International Journal of Economics and Finances. 6(9) : $95-106$.

Dewi, W.K, Yurniwati \& Rahman, A. 2018. The Effect of Financial Literacy and Financial

Access to the Performance of SMEs Small and Medium Enterprises) in the Trade Sector of Padang City. International Journal of Progressive Sciences and High Tecnologies.

Dinas Koperasi dan UMKM. 2020. Laporan UMKM Kota Padang 2019.

Ebuka, Arachie Augustine \& Hope Ngozi Nzewi \& Emejulu Gerald \& Kekeocha Mary Ezinne.

2020. Digital Literacy in a Post Coronavirus Era : A Management Perspective for Small

Business in Africa. Annal of Management and Organization Research (AMOR). 1(3) :

$203-212$. 
Forsyth, Patrick. 1990. Manajemen Penjualan. Jakarta : PT Elex Media Komputindo.

Ghazali, Imam. 2006. Desain Penelitian Kuantitatif dan Kualitatif Untuk Akuntansi, Bisnis dan Ilmu Sosial Lainnya. Semarang : Universitas Diponegoro.

Hary, Samuel Wahyu. 2020. Hubungan E-Commerce dan Literasi Keuangan Terhadap

Kelansungan UMKM Di Boyolali. Jurnal Akuntansi Universitas Bengkulu. 10(1).

Houssaini, Mohd. Sqalli \& Jeaslin Decossa, Aya Slaoui. 2020. Internalization of SMEs : Between Global Value Chains and E-Commerce. International Journal of Small and Medium Enterprises. 3(2) : $1-16$.

Hudson, M.A, Smart \& M.Bourne. 2001. Theory and Practice in SME's Performance Measurement Systems. International Journal of Operations \& Production Management. 21(8) : 1096 - 1115.

Kementerian Pendidikan dan Kebudayaan. 2017. Materi Pendukung Literasi Digital. Jakarta.

Knight, G. 2001. Enterpreneurship and Strategy in the International SME's. Strategic Management Journal. 22(67) : $565: 586$.

Kulathunga, K.M.M.C.B \& Jianmu Ye \& Saurabh Sharma \& P.R. Weerathunga. 2020. How does Technological and Financial Literacy Influence SME Performance : Mediating Role of ERM Practices. Journal of Information. 11 (297) : $2-20$. thr 21 st Century. Volume VI, PISA, OECD Publishing.
Kurihara, Y. 2013. Does Financial Skill Promote Economic Growth? International Journal of Humanities Social Science. 3(8) : $92-97$.

Liu, Baohua \& Jiancheng Wang \& Kam C.Chan. 2020. The Impact of Enterpreneurs's Financial Literacy on Innovation within Small and Medium Sized Enterprises.

International Small Business Journal. 30 September.

Lukonongo, Innutu and Bikas Joshi. 2020. Harnessing Digital Technologies to Promote SMEs in the MENAP Region. IMF $e$ Library. Juli 2020. ISBN 9781513550770

Lusardi, A \& Mitchell, O. 2007. Financial Literacy and Retirement Preparedness : Evidence and Implication for Financial Education. Business Economics : $35-44$.

OECD. 2014. PISA 2012 Results : Students and Money Financial Literacy Skills for thr 21 st Century. Volume VI, PISA, OECD Publishing.

OECD. 2016. Assesment and Analytical Framework : Science, Reading, Mathematic and Financial Literacy. Publishing Paris.

OJK. 2016. Strategi Nasional Literasi Keuangan. Jakarta : Otoritas Jasa Keuangan.

Opoku, A. 2015. Financial Literacy Among Senior High School Students Evidence from

Ghana. Thesis. Kwame Nkrumah University.

Palameta, B, Nguyen, C, Hui, T \& Gyarmati, D. 2016. The Link Between Financial Confidence and Financial Outcomes Among Working Aged Canadian. The 
Social Research and Demonstration Corporation.

Partomo, T.S dan Soejoedono, A.R. 2004. Ekonomi Skala Kecil/Menengah dan Koperasi Jakarta : Ghalia Indonesia.

Putri, A.S. 2019. Diakses http://www.kompas.com/skola/re $\mathrm{ad} / 2019 / 12 / 20 / 120000469 /$ peranumkm- dalamperekonomianindonesia?page $=$ all. Tanggal 7 Juli 2021.

Ranatunga, Rvspk \& H.M.S Priyanath \& Megama Rgn. 2020. Digital Literacy, Business

Uncertainty \& Economic Performance : An Empirical Study of Small Businesses in Sri Lanka. International Journal of Academic Research in Business \& Social Science. 10(5): 50-76.

Remund, D \& Huston. 2010. Financial Literacy Explicated : The Case for a Clearer Definition in an Increasingly Complex Economy. The Journal of Consumer Affairs. 44(2) : 276 - 295.

Riel, J. Christian S. \& Hinson, B. 2012. Charting Digital Literacy : A Framework for Information Technology and Digital Skill Education in the Community College. PresentationInnovation.

Rosa, Yenni Del. 2015. Pengaruh Karakteristik Manajerial Terhadap Intensi Turn Over Karyawan dan Kinerja UMKM Bukittinggi. Jurnal Menara Ekonomi. 1(1). April 2015.

$83-92$.

Rosa, Yenni Del, Abdilla, mohammad, 2019. Peluang Bisnis UMKM Pangan Di Kecamatan IV Angkek Agam. Jurnal Menara Ekonomi. 5(1) : April 2019. 93 102.
Rosa, Yenni Del .dan Idward. 2019. Pengaruh Inflasi dan Suku Bunga Terhadap Omset

UMKM Kota Padang. Jurnal Menara Ekonomi. 5(3) : Oktober $2019: 133-145$.

Rosa, Yenni Del \& Idward. 2020. Kajian Omset UMKM Kota Padang Saat Pandemi Covid 19 Ditinjau Dari Faktor Internal dan Eksternal. Jurnal Ekonomi dan Bisnis DharmaAndalas. 23 (1). Januari 2021. : 195 - 207.

Samuelson, P.A \& William D.N. 2001. Ilmu Makroekonomi Edisi 17. Jakarta : PT Media Global Edukasi. 5(1). April 2020 : 63 92.

Sekaran, Uma. 2006. Research Methods for Business. Buku 2.Jakarta : Salemba Empat.

Shinozaki, Shigehiro \& Lakshman N.Rao. 2021. Covid 19 Impact on Micro Small and Medium Sized Enterprises Under the Lockdown : Evidence from a Rapid Survey in the Phlipippiness. ADBI Working Paper Series No. 1216. February 2021. Asia Development Bank Institute Kasumigaseki Buliding Chiyoda-ku Tokyo. Japan.

Soetiono, K \& Setiawan, C. 2018. Literasi dan Inklusi Keuangan Indonesia. Depok : Rajawali Press.

Sulistyawan, Wawan. 2020. Dampak Covid $19 \quad$ Terhadap

Keberlangsungan Bisnis

Makalah Webinar MM UPS Tegal.

Suryani, S \& Ramadhan, S. 2017. Analisis Literasi Keuangan Pada pelaku Usaha Mikro Di Kota Pekanbaru. Journal of Economic Business and Accounting. 1(1) : $12-22$. 
Swastha, Basu. 1993. Manajemen Pemasaran Modern. Yogyakarta : Liberty.

Swastha, Basu dan Irawan. 1990. Manajemen Pemasaran Modern. Yogyakarta : Liberty.

Tambunan, Tulus. 2012. UMKM Di Indonesia : Isu-Isu Penting. Jakarta : LP3ES.

Tuffour, Yoseph Kwadwo \& Awurabena A.A \& Ernestina Otuka Amartey. 2020. Assesing the Effect of Financial Literacy Among Managers on the Performance of Small-Scale Enterprises. Global Business Review. 4 (1) : 1 - 18

Tustin, D. 2016. An Impact Assessment of a Prototype Financial Literacy Flagship Programme in a Rural South African Setting. Journal of Business Management. 4(9) : 1894 - 1902.

Umar, Husein. 2015. Metode Penelitian Untuk Skripsi dan Thesis Bisnis. Jakarta : Rajagrafindo Persada.

Undang-Undang No. 20 Tahun 2008 Tentang UMKM.

Undang-Undang No. 19 Tahun 2019 Tentang Informasi Transaksi Elektronik.

Viswanathan, Radhakrishnan \& Arnesh Telukdarie. 2021. A System Dynamics Approach to SME Digitalization. Procedia Computer Science. Voleme 180 : $816-824$.

Wagland, S.P. and Taylor, S. 2009. When it comes to Financial Literacy is Gender Really an Issues? The Australiasian AccountingBusiness \& Finance Journal. May 2009. 3(1) : 3

Widiyanti, R, Damayanti \& Maewanti, F. 2017. Pengaruh Financial Literacy Terhadap Keberlansungan Usaha Pada UMKM Desa Jatisari. Jurnal
Ilmiah Manajemen \& Bisnis. 18(2) : $153-163$.

World Bank. 2016. Trends in the Objectives of National Financial Capital Strategies (p.9).

Worl Economic Forum. 2015. Latar Belakang Global Baru. Davos (Swiss). Tanggal 21 - 24 Januari 2015.

Ye, J. \& Kalathunga, K. 2019. How Does Financial Literacy Promote Sustainability in SMEs A Developing Country Perspective. Journal Sustainability. 11(2990) : $1-21$.

Yusuf, A.Muri. 2014. Metode Penelitian : Kuantitatif, Kualitatif \& Penelitian Gabungan Jakarta : Prenadamedia Grup.

Internet

https://internetsehat.id/literasi

https://www.lsisis.org/pakar-literasimedia-penting-untuk-masyarakat-digital/ https://stffnew.uny.ac.id/upload/1323096 82/pengabdian/membangun-karakterbangsa-melalui-literasi digital.pdf https://duta.co/menginspirasipendidikan-dengan-literasi-digital 